\title{
TRPV4 as a target for bladder overactivity
}

\section{Patrizia Angelico and Rodolfo Testa*}

\author{
Address: Pharmaceutical R\&D Division, RECORDATI S.p.A., Via Civitali 1, 20148 Milano, Italy \\ *Corresponding author: Rodolfo Testa (temax5@fastwebnet.it) \\ FI000 Biology Reports 2010, 2:12 (doi:10.34I0/B2-12)
}

The electronic version of this article is the complete one and can be found at: http://fl000.com/reports/biology/content/2/12

\begin{abstract}
Several papers published in the last 2-3 years suggest that transient receptor potential vanilloid 4 (TRPV4) channels are candidates as mechanosensors in the urinary bladder (including human) and indicate that modulation (inhibition) of these channels could represent a novel therapy for overactive bladder and storage dysfunction. The effects of only agonists on the bladder have been described up to now, although some compounds endowed with antagonistic activity were reported in the last year. Therefore, it is to be hoped that the effects of these compounds in different models of bladder overactivity will be evaluated.
\end{abstract}

\section{Introduction and context}

Transient receptor potential vanilloid 4 (TRPV4), a member of the TRP superfamily of cation channels, is a $\mathrm{Ca}^{2+}$-permeable channel. The TRPV family contains six mammalian members: TRPV1 to TRPV6. TRPV1 to TRPV4 are all heat-activated channels that are nonselective for cations and modestly permeable to $\mathrm{Ca}^{2+}$, with permeability ratios $(\mathrm{PCa} / \mathrm{PNa})$ of between about 1 and 10. In addition, TRPV1 to TRPV4 function as chemosensors for a broad array of endogenous and synthetic ligands. The properties of the two other members of this subfamily, TRPV5 and TRPV6, are quite different from those of TRPV1 to TRPV4. They are the only highly $\mathrm{Ca}^{2+}$ selective channels in the TRP family, and both are tightly regulated by the intracellular calcium ion concentration ([Ca $\left.\left.{ }^{2+}\right] \mathrm{i}\right)$ ([1] and references therein).

With regard to TRPV4, this channel is activated by a wide variety of physical and chemical stimuli $[1,2]$. The activation of TRPV4 may be induced by hypotonic stimuli in response to hypotonicity-induced cell swelling [3-5] and shear stress [6]. Alternatively, TRPV4 can be activated by diverse chemical stimuli such as the

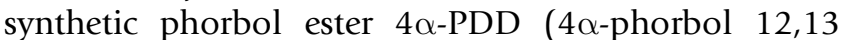
didecanoate), anandamide metabolites such as arachidonic acid and epoxyeicosatrienoic acids, and moderate warmth $\left(>27^{\circ} \mathrm{C}\right)[7-10]$.
TRPV4 is widely expressed throughout the body, including renal epithelium, auditory hair cells, skin keratinocytes, hippocampus neurons, endothelial cells, and urinary bladder epithelium, thereby contributing to numerous physiological processes such as osmoregulation, hearing, thermal and mechanical hyperalgesia, neural activity in the brain, skin barrier recovery, and cell volume regulation. Therefore, the TRPV4 channel is now considered a multimodal transducer in various tissues and cells $[11,12]$.

The role of TRPV4 channels in bladder function was first reported by Gevaert et al. [13]. These authors demonstrated that TRPV4 was expressed mainly in bladder basal and intermediate urothelial cells and functioned as a $\mathrm{Ca}^{2+}$ influx pathway activated by hypotonic cell swelling and induced by the specific TRPV4 agonist $4 \alpha$-PDD (Figure 1) in these cells. Furthermore, they found that mice lacking TRPV4 displayed a severely disturbed urinevoiding pattern. Cystometry experiments revealed that TRPV4 knockout mice exhibited a lower frequency of voiding contractions as well as a higher frequency of nonvoiding contractions. No significant differences in amplitude or duration of both voiding and nonvoiding contractions were found. The total amount of urine per cystometry-induced voiding episode was greater in TRPV4 knockout mice in comparison with wild-type 
Figure I. Chemical structures of selected transient receptor potential vanilloid 4 (TRPV4) agonists and of the TRPV4 antagonist RN-I734

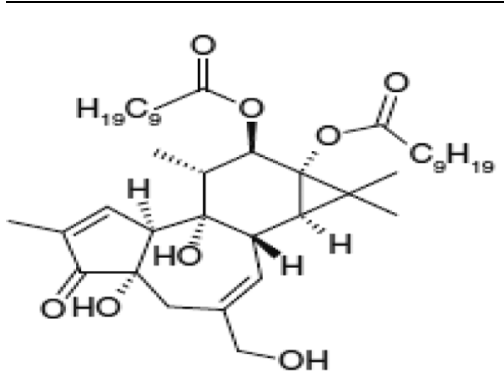

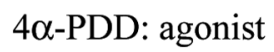

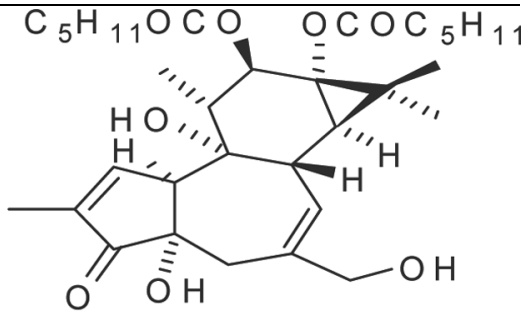

A P P $441-1$ : agonist<smiles>CCCCC/C=C\C/C=C\CCCC(=O)O</smiles>

5',6'-EET: agonist<smiles>C=C(N[C@@H](CC(C)C)C(=O)N1CCN(C(=O)[C@H](CO)NS(=O)(=O)c2ccc(Cl)cc2Cl)CC1)c1cc2ccccc2s1</smiles>

GSK1016790A: agonist<smiles>CC(C)NCCN(C(C)C)S(=O)(=O)c1ccc(Cl)cc1Cl</smiles>

RN-1734: antagonist<smiles>[R][Y]N([R])C([R])([R])[X]OC(=O)C([R])N([R])Br</smiles>

diazabicyclo[2.2.1]hept-2-yl analogs: antagonists

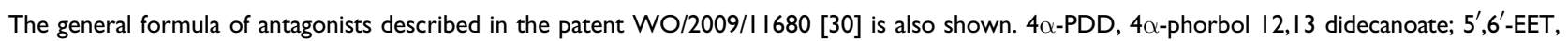

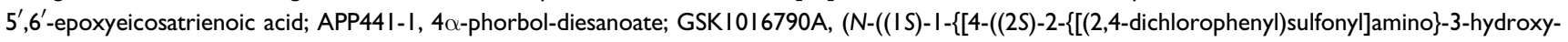
propanoyl)-I-piperazinyl]carbonyl\}-3-methylbutyl)-I-benzothiophene-2-carboxamide; RN-1734, 2,4-dichloro-N-isopropyl-N-[2-(isopropylamino) ethyl]benzenesulfonamide.

animals. Finally, in in vitro experiments, they reported a lower amplitude of spontaneous contractions and a decrease in stretch-evoked intravesical ATP release in bladders from TRPV4 knockout mice.

Birder et al. [14] confirmed that rat urothelial cells also express functional TRPV4 channels since TRPV4 mRNA and protein are both detectable. The exposure of these cells to the selective TRPV4 agonists $4 \alpha-P D D$ and $5^{\prime}, 6^{\prime}$-EET $\left(5^{\prime}, 6^{\prime}\right.$-epoxyeicosatrienoic acid) (Figure 1) induced $\mathrm{Ca}^{2+}$ influx and ATP release, both of which can be blocked by the antagonist ruthenium red. Furthermore, the hypo-osmolarity-evoked ATP release from urothelial cells is potentiated by $4 \alpha-\mathrm{PDD}$, and $4 \alpha-$ PDD-evoked $\left[\mathrm{Ca}^{2+}\right] \mathrm{i}$ responses are inhibited by hyperosmolarity. It is also reported that during continuous infusion cystometrograms in awake rats, intravesical administration of $4 \alpha$-PDD increased maximal micturition pressure, specifically by augmenting the portion of each intravesical pressure wave that follows highfrequency urethral oscillations and voiding. This effect was prevented by intravesical pretreatment with a nonselective ATP receptor antagonist or systemic treatment with a selective P2X3 purinergic antagonist or urethane anesthesia but was unaffected by capsaicin pretreatment or denervation of the urethral sphincter. $4 \alpha-P D D$, however, did not alter the contractility to electrical stimulation of excised bladder strips.

By using a novel TRPV4 channel activator (GSK1016790A) (Figure 1) that is about 300 -fold more potent than the commonly used TRPV 4 activator $4 \alpha-P D D$, Thorneloe et al. [15] showed that this compound elicited $\mathrm{Ca}^{2+}$ influx in mouse and human TRPV4-expressing 
human embryonic kidney (HEK) cells, and it evoked a dose-dependent activation of TRPV4 whole-cell currents. In the same paper, it is reported that TRPV4 mRNA was detected in urinary bladder smooth muscle and urothelium of mouse bladders but was absent in TRPV4 knockout bladders. Accordingly, TRPV4 activation with GSK1016790A contracted wild-type mouse bladders in vitro, an effect that was undetected in TRPV4 knockout bladders. In vivo, cystometry performed in conscious mice revealed an enhanced bladder capacity in the TRPV4 knockout animals, and infusion of GSK1016790A into the bladders of normal mice induced bladder overactivity with no effect in TRPV4 knockout animals.

\section{Major recent advances}

In a more recent study, Yamada et al. [16] morphologically confirmed by immunoblotting and immunohistochemical studies that TRPV4 (but not TRPV1) channels were expressed in mouse urothelial cells, especially at the basal plasma membrane domains of the basal urothelial cells, and that the isolated urothelial cells showed marked increases in $\left[\mathrm{Ca}^{2+}\right] \mathrm{i}$ when $4 \alpha$-PDD and hypotonic stimuli were applied. Similarly, Xu et al. [17] showed that the TRPV1 agonist capsaicin, which activated TRPV1 currents in HEK cells expressing TRPV1, was unable to evoke current in freshly isolated guinea pig urothelial cells, and other authors [18] demonstrated that $4 \alpha-\mathrm{PDD}$ elicited transient currents in a high percentage of cultured rat urothelial cells $(>70 \%)$ whereas capsaicin elicited transient currents in a moderate percentage of cells (approximately 25\%).

Similar results were obtained by Mochizuki et al. [19], who showed that the TRPV4 mRNA is uniquely abundant among the TRP channels that reportedly exist in urinary bladder epithelium. In an immunohistochemical study, TRPV4 was localized in basal and intermediate urothelial cell layers of mice bladders, and TRPV4 expression was also confirmed in primary cell cultures. The functional expression of TRPV4 in urothelial cells was evidenced by using the selective agonist $4 \alpha-\mathrm{PDD}$ in $\mathrm{Ca}^{2+}$ imaging experiments. Furthermore, the authors confirmed that in vitro mechanical stretch stimulation of urothelial cells activated TRPV4, leading to increased $\left[\mathrm{Ca}^{2+}\right] \mathrm{i}$ and ATP release. These findings were also presented elsewhere [20].

At the most recent annual meeting of the International Continence Society (San Francisco, CA, USA, 29 September to 3 October 2009), several posters about the role of TRPV4 channels in bladder physiology and their possible involvement in bladder overactivity were presented.

Everaerts et al. [21] showed that $4 \alpha$-phorbol-diesanoate (APP441-1) (Figure 1), another specific agonist for
TRPV4 [22], induced an increase of $\left[\mathrm{Ca}^{2+}\right] \mathrm{i}$ in urothelial cells from wild-type mice but not in cells from TRPV4 knockout mice in vitro. In conscious rats, application of APP441-1 induced a significant increase in voiding pressure and decrease in the intercontractile interval. In urethane anesthetized wild-type mice, APP441-1 induced bladder overactivity, characterized by a decrease in the intercontractile interval, but did not induce any effects in the TRPV4 knockout mice.

An evaluation of the functional expression of different TRP channels (TRPA1, TRPV1, TRPV2, TRPV4, and TRPM8) in mouse urothelial cells was reported by Everaerts et al. [23]. Quantitative polymerase chain reaction showed very low levels of TRPA1 and TRPV1 mRNA but high levels of TRPV4 and TRPV2 mRNA. TRPM8 mRNA was not detected. Functional analysis using $\mathrm{Ca}^{2+}$ imaging showed that the majority of cultured urothelial cells responded to $4 \alpha-P D D$, indicating an important functional role for TRPV4 in these cells.

Since TRPV4 channels are activated by mechanical stretch, Janssen et al. [24] evaluated the co-localization of these channels and adherence junctions (E-cadherin) in the urothelium of the human kidney, ureter, and bladder. A co-localization between TRPV4 and E-cadherin was found throughout the urogenital tract. The co-localization of TRPV 4 and adherence junctions in the urothelium of the bladder (as well as of the other tissues) means that TRPV4 is connected to the rigid structural network that includes the intracellular actin cytoskeleton and extracellular anchoring cell junctions and confirms that TRPV4 is involved in the sensation of stretch in the urothelium of human bladder. The same authors [25] reported that such a co-localization between TRPV4 and E-cadherin was also seen in the urothelium of normal mouse bladder but not in the TRPV4 knockout mice.

Finally, Miyamoto et al. [26] showed that in patients with benign prostatic hyperplasia or bladder outlet obstruction, bladder urothelium showed higher expressions of TRPA1, TRPV4, and TRPV1, confirming that these channels are candidates as mechanosensors in the human urinary bladder and indicating that modulation of these channels could be a novel therapy for overactive bladder and storage dysfunction.

\section{Future directions}

The findings reported above indicate that TRPV4 is stimulated during distension of the bladder urothelium and could contribute to abnormal overactivity of the bladder in pathological conditions. As reported by Thorneloe et al. [15], nifedipine reversed GSK1016790A 
contractions, indicating a prominent role for L-type $\mathrm{Ca}^{2+}$ channels in mediating TRPV4 contractions. In addition, TRPV4 stimulation induces ATP release from the urothelium $[13,14]$, and it has been reported that intravesical administration of ATP activates bladder afferent nerves and in turn triggers bladder hyperactivity [27]. It will be extremely interesting, therefore, to evaluate the effects of antagonists of the TRPV4 receptor in different models of bladder overactivity, although so far the activity of any antagonist has not been reported in the literature.

The first report about small molecules showing selective antagonistic activity in the human TRPV4 receptor expressed in HEK-293 cells was a poster presented by Hydra Biosciences, Inc. (Cambridge, MA, USA) at the 2008 meeting of the Society for Neuroscience [28].

More recently, Vincent et al. [29], by evaluating a library of commercial compounds, showed that one of these, namely RN-1734 (Figure 1), is endowed with TRPV4 antagonist properties. By using electrophysiology and intracellular calcium influx in rat and mouse TRPV4 channels, these authors demonstrated that RN-1734 completely inhibited both ligand- and hypotonicityactivated TRPV4. In addition, RN-1734 was found to be selective for TRPV4 in a TRP selectivity panel including TRPV1 and TRPV3. Furthermore, a recent patent from GlaxoSmithKline (Uxbridge, Middlesex, UK) [30] describes a series of diazabicyclo[2.2.1]hept-2-yl analogs endowed with TRPV4 antagonistic properties for the treatment or prevention of different diseases, including overactive bladder (Figure 1).

It has previously been reported $([13,14]$ and references therein) that in the urinary bladder, the closely related TRPV1 channel is expressed in sensory nerve terminals, in the epithelial cells (urothelium), and in interstitial cells. This channel can be gated by the pungent vanilloid compound capsaicin and also by a number of other noxious stimuli, including intense heat $\left(>43^{\circ} \mathrm{C}\right)$, protons $(\mathrm{pH}<5)$, and certain lipid molecules, namely anandamide, $\mathrm{N}$-arachadonyl dopamine, and 5-hydroperoxyeicosatetraenoic acid [31].

Analysis of TRPV1 knockout mice indicated that TRPV1 participates in normal bladder function. Mice lacking TRPV1 display a higher frequency of low-amplitude nonvoiding bladder contractions in comparison with wild-type animals. TRPV1 is required for bladder stretch detection, which involves the stretch-evoked release of ATP and nitric oxide. Accordingly, TRPV1 antagonists increased the threshold for activation of the micturition reflex in the anesthetized rat volume-induced micturition reflex model and also inhibited detrusor overactivity induced by intravesical capsaicin and intravesical citric acid [32]. Furthermore, patients suffering from neurogenic bladder hyperreactivity have experienced relief from both urinary frequency and urgency after intravesical desensitization with TRPV1 agonists [33,34]. However, a problem arising with the administration of TRPV1 blockers in animals is the induction of hyperthermia, an effect observed in rats, mice, dogs, and monkeys [35].

At present, potent small-molecule TRPV1 antagonists are undergoing clinical trials for chronic pain. Clinical development of TRPV1 antagonists also demonstrated that many drug candidates evoke a febrile reaction that varies among patients, probably owing to the TRPV1 gene polymorphism that might be a cause of the intersubject variability in response to TRPV1 antagonists [36].

Whether or not TRPV1 involvement in thermoregulation will impede clinical development of TRPV1 antagonists is still an open question [35]. Although the characteristics of TRPV1 and TRPV4 are quite different [1], this aspect should be carefully taken into consideration.

\section{Abbreviations}

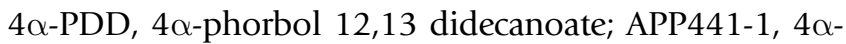
phorbol-diesanoate; $\left[\mathrm{Ca}^{2+}\right] \mathrm{i}$, intracellular calcium ion concentration; GSK1016790A, (N-((1S)-1-\{[4-((2S)2-\{[(2,4-dichlorophenyl)sulfonyl $]$ amino $\}$-3-hydroxypropanoyl)-1-piperazinyl]carbonyl \}-3-methylbutyl)-1-benzothiophene-2-carboxamide; HEK, human embryonic kidney; RN-1734, 2,4-dichloro-N-isopropyl-N-[2-(isopropylamino) ethyl]benzenesulfonamide; TRP, transient receptor potential; TRPV, transient receptor potential vanilloid.

\section{Competing interests}

The authors declare that they have no competing interests.

\section{Acknowledgments}

The authors thank Giovanni Appendino for the chemical structure of APP441-1.

\section{References}

I. Nilius B, Owsianik G, Voets T, Peters JA: Transient receptor potential cation channels in disease. Physiol Rev 2007, 87: 165-2|7.

2. Nilius B, Watanabe H, Vriens J: The TRPV4 channel: structurefunction relationship and promiscuous gating behaviour. Pflugers Arch 2003, 446:298-303.

3. Strotmann R, Harteneck C, Nunnenmacher K, Schultz G, Plant TD: OTRPC4, a nonselective cation channel that confers sensitivity to extracellular osmolarity. Nat Cell Biol 2000, 2:695-702.

4. Liedtke W, Choe Y, Marti-Renom MA, Bell AM, Denis CS, Sali A, Hudspeth AJ, Friedman JM, Heller S: Vanilloid receptor-related osmotically activated channel (VR-OAC), a candidate vertebrate osmoreceptor. Cell 2000, I03:525-35. 
5. Nilius B, Prenen J, Wissenbach U, Bodding M, Droogmans G: Differential activation of the volume-sensitive cation channel TRPI 2 (OTRPC4) and volume-regulated anion currents in HEK-293 cells. Pflugers Arch 200I, 443:227-33.

6. Gao X, Wu L, O'Neil RG: Temperature-modulated diversity of TRPV4 channel gating: activation by physical stresses and phorbol ester derivatives through protein kinase $\mathbf{C}$-dependent and -independent pathways. J Biol Chem 2003, 278:27 I 29-37.

7. Watanabe H, Davis JB, Smart D, Jerman JC, Smith GD, Hayes P, Vriens J, Cairns W, Wissenbach U, Prenen J, Flockerzi V, Droogmans G, Benham CD, Nilius B: Activation of TRPV4 channels (hVRL-2/mTRPI2) by phorbol derivatives. I Biol Chem 2002, 277:13569-77.

8. Watanabe H, Vriens J, Suh SH, Benham CD, Droogmans G, Nilius B: Heat-evoked activation of TRPV4 channels in a HEK293 cell expression system and in native mouse aorta endothelial cells. J Biol Chem 2002, 277:47044-5I.

9. Guler AD, Lee H, lida T, Shimizu I, Tominaga M, Caterina M: Heatevoked activation of the ion channel, TRPV4. J Neurosci 2002, 22:6408-14.

FI000 Factor 3.0 Recommended Evaluated by Ellen A Lumpkin 18 Oct 2002

10. Nilius B, Vriens J, Prenen J, Droogmans G, Voets T: TRPV4 calcium entry channel: a paradigm for gating diversity. Am J Physiol Cell Physiol 2004, 286: C195-205.

II. Plant TD, Strotmann R: TRPV4. Handb Exp Pharmacol 2007, 179: 189-205.

12. Everaerts W, Nilius B, Owsianik G: The vallinoid transient receptor potential channel Trpv4: from structure to disease. Prog Biophys Mol Biol 2009, [Epub ahead of print].

13. Gevaert T, Vriens J, Segal A, Everaerts W, Roskams T, Talavera K, Owsianik G, Liedtke W, Daelemans D, Dewachter I, Van Leuven F, Voets $T$, De Ridder D, Nilius B: Deletion of the transient receptor potential cation channel TRPV4 impairs murine bladder voiding. J Clin Invest 2007, I I 7:3453-62.

FI000 Factor 4.8 Must Read

Evaluated by Rodolfo Testa 20 Nov 2007, Jens Leipziger 6 Feb 2008

14. Birder L, Kullmann FA, Lee H, Barrick S, de Groat W, Kanai A, Caterina M: Activation of urothelial transient receptor potential vanilloid 4 by 4alpha-phorbol 12,13-didecanoate contributes to altered bladder reflexes in the rat. J Pharmacol Exp Ther 2007, 323:227-35

FI000 Factor 3.2 Recommended

Evaluated by Jens Leipziger 06 Feb 2008, Rodolfo Testa 2I Feb 2008

15. Thorneloe KS, Sulpizio AC, Lin Z, Figueroa DJ, Clouse AK, McCafferty GP, Chendrimada TP, Lashinger ES, Gordon E, Evans L, Misajet BA, Demarini DJ, Nation JH, Casillas LN, Marquis RW, Votta B], Sheardown SA, Xu X, Brooks DP, Laping NJ, Westfall TD: N-((IS)-I-\{[4-((2S)-2-\{[(2,4-dichlorophenyl)sulfonyl]amino\}3-hydroxypropanoyl)-I-piperazinyl]carbonyl\}-3-methylbutyl)-I-benzothiophene-2-carboxamide (GSKI0I6790A), a novel and potent transient receptor potential vanilloid 4 channel agonist induces urinary bladder contraction and hyperactivity: Part I. J Pharmacol Exp Ther 2008, 326:432-42.

16. Yamada T, Ugawa S, Ueda T, Ishida $Y$, Kajita K, Shimada S: Differential localizations of the transient receptor potential channels TRPV4 and TRPVI in the mouse urinary bladder. J Histochem Cytochem 2009, 57:277-87.

FI000 Factor 3.0 Recommended

Evaluated by Rodolfo Testa II Dec 2008

17. Xu X, Gordon E, Lin Z, Lozinskaya IM, Chen Y, Thorneloe KS: Functional TRPV4 channels and an absence of capsaicinevoked currents in freshly-isolated, guinea-pig urothelial cells. Channels (Austin) 2009, 3:156-60.

18. Kullmann FA, Shah MA, Birder LA, de Groat WC: Functional TRP and ASIC-like channels in cultured urothelial cells from the rat. Am J Physiol Renal Physiol 2009, 296:F892-901.
19. Mochizuki T, Sokabe T, Araki I, Fujishita K, Shibasaki K, Uchida K, Naruse K, Koizumi S, Takeda M, Tominaga M: The TRPV4 cation channel mediates stretch-evoked $\mathrm{Ca}+$ influx and ATP release in primary urothelial cell cultures. J Biol Chem 2009, 284:2। $257-64$.

FI000 Factor 6.0 Must Read

Evaluated by Rodolfo Testa 07 Aug 2009

20. Mochizuki T, Araki I, Yoshiyama M, Takeda M: Functional role of the TRPV4 cation channel in stretch-evoked $\mathrm{Ca2}+$ influx and ATP release in mouse urothelial primary cultures. Poster presented at International Continence Society 39th Annual Meeting; 29 September - 3 October 2009, San Francisco, CA, USA. Poster 108.

21. Everaerts W, Leten C, Appendino G, Voets T, Nilius B, De Ridder D: APP44I-I, a novel TRPV4 agonist is able to induce bladder overactivity in rats and mice. Poster presented at International Continence Society 39th Annual Meeting; 29 September - 3 October 2009, San Francisco, CA, USA. Poster 104.

22. Klausen TK, Pagani A, Minassi A, Ech-Chahad A, Prenen J, Owsianik G, Hoffmann EK, Pedersen SF, Appendino G, Nilius B: Modulation of the transient receptor potential vanilloid channel TRPV4 by 4alpha-phorbol esters: a structure-activity study. I Med Chem 2009, 52:2933-9.

23. Everaerts W, Owsianik G, Vriens J, Talavera K, Van Haute C, Nilius B, De Ridder D: Functional characterisation of TRP channels in mouse urothelium: a major role for TRPV4. Poster presented at International Continence Society 39th Annual Meeting; 29 September - 3 October 2009, San Francisco, CA, USA. Poster II 0.

24. Janssen DAW, Jansen KCFJ, Schalken JA, Heesakkers J: TRPV4 as stretch-receptor; co-localization between TRPV4 and adherence junctions in urothelium of human kidney, ureter \& urinary bladder. Poster presented at International Continence Society 39th Annual Meeting; 29 September - 3 October 2009, San Francisco, CA, USA. Poster 136.

25. Janssen DAW, Jansen KCFJ, Schalken JA, Heesakkers J: TRPV4 as a mechanoreceptor in the human bladder; a co-localization between TRPV4 and adherence junctions the urothelium. Poster presented at International Continence Society 39th Annual Meeting; 29 September - 3 October 2009, San Francisco, CA, USA. Poster 137.

26. Miyamoto T, Mochizuki T, Zakohji H, Kobayashi H, Yoshiyama M, Araki I, Takeda M: The expression of transient receptor potential (TRP) $\mathrm{V4}, \mathrm{AI}$, and $\mathrm{VI}$ in the human bladder mucosa of normal and bladder outlet obstruction - a novel mechanism in the obstruction-induced bladder overactivity. Poster presented at International Continence Society 39th Annual Meeting; 29 September - 3 October 2009, San Francisco, CA, USA. Poster 236.

27. Zhang $X$, lgawa $Y$, Ishizuka $O$, Nishizawa $O$, Andersson KE: Effects of resiniferatoxin desensitization of capsaicin-sensitive afferents on detrusor over-activity induced by intravesical capsaicin, acetic acid or ATP in conscious rats. Naunyn Schmiedebergs Arch Pharmacol 2003, 367:473-9.

28. Fanger CM, McNamara CR, Strassmaier T, Witek J, Agueev V, Moran MM, Zhen X: Identification of novel TRPV4 channel modulators. Paper presented at Society for Neuroscience 38th Annual Meeting; 15-19 November 2008, Washington, DC, USA. Poster C58. [http://www.abstractsonline.com/Plan/ViewAbstract.aspx? sKey $=\mathrm{d} 4348 \mathrm{a} 68-5 \mathrm{c} 03-442 \mathrm{I}-8785-9523 \mathrm{e} 45 \mathrm{adbc} 4 \& \mathrm{cKey}=8790 \mathrm{cdde}-$ 3 Ia2-40|3-bb0d-90If3c776Ic2].

29. Vincent $F$, Acevedo A, Nguyen MT, Dourado M, Defalco J, Gustafson A, Spiro P, Emerling DE, Kelly MG, Duncton MA: Identification and characterization of novel TRPV4 modulators. Biochem Biophys Res Commun 2009, 389:490-4.

30. Cheung M, Du Z, Eidam HS, Fox RM, Marquis RW: TRPV4 antagonists. Patent WO/2009/I I 1680. I I September 2009.

3I. Caterina MJ, Schumacher MA, Tominaga M, Rosen TA, Levine JD, Julius D: The capsaicin receptor: a heat-activated ion channel in the pain pathway. Nature 1997, 389:816-24.

32. Cefalu JS, Guillon MA, Burbach LR, Zhu QM, Hu DQ, Ho MJ, Ford AP, Nunn PA, Cockayne DA: Selective pharmacological blockade of 
the TRPVI receptor suppresses sensory reflexes of the rodent bladder. J Urol 2009, 182:776-85.

FI000 Factor 3.0 Recommended

Evaluated by Rodolfo Testa 30 Jun 2009

33. Chancellor MB, de Groat WC: Intravesical capsaicin and resiniferatoxin therapy: spicing up the ways to treat overactive bladder. J Urol 1999, 162:3-II.
34. Fowler C: Intravesical treatment of overactive bladder. Urology 2000, 55:60-4.

35. Gavva NR: Body-temperature maintenance as the predominant function of the vanilloid receptor TRPVI. Trends Pharmacol Sci 2008, 29:550-7.

36. Khairatkar-Joshi N, Szallasi A: TRPVI antagonists: the challenges for therapeutic targeting. Trends Mol Med 2009, 15:14-22. 